\title{
Psychoanalytical Study of Folktale
}

\author{
Ritamani Das \\ Assistant Professor, Deptt. Of Education, Kokrajhar Govt. College, Kokrajhar, Assam
}

\begin{abstract}
Folktale is one of the popular sources of entertainment. From time immemorial it has been considered as an important asset of our society. They are the literary creations of a society which may be taken as the common property shared by all. Psychoanalysis is a tool by which one can interpret the meaning of folktale. Such kind of analysis is essential to understand the society and its people. Tales told for amusement has become a subject of serious study in the $19^{\text {th }}$ century. It reflects the fantasies of people metaphorically. The analysis and interpretation of metaphors provide insights into the social problems and behaviour of people everywhere. The aim of this study is to highlight the significance of folktale interpretation for proper understanding of the society and its associated problems. This study is confined to the folktale analysis of Freudian method. Some other psychological or sociological approaches may also prove useful in the analysis and interpretation of folktale. For this, other methods or techniques of analysis should be used in combination with psychoanalytical method to explore voices of the people.
\end{abstract}

Keywords: Defence mechanism, Folktale, Interpretation, Psychoanalysis, Repression.

\section{Introduction}

The trend of modern folklore research has now given more importance on the analysis of different folklore materials. It is because of the fact that the study of folklore remains incomplete without interpretation. In order to analyse various items of folklore, the folklorists have used different methods. The area of interpretation in folklore has also been influenced by psychoanalytical theory of Sigmund Freud. The application of this theory is useful because it helps us to understand the nature of human mind. Again, it helps us to interpret the symbolic meanings found in different folklore items. Till now, the folklorists have interpreted various items of folklore following psychoanalytical methods.

Folktale - one of the traditional sources of entertainment is as old as mankind. Folktale is an important sub-division of prose narratives which constitutes the major area of folklore. Folktales are fictional compositions handed down orally from generation to generation either in the oral form or in the written form. They are the literary creations of a society which may be considered as the common property shared by all members of a society. Folktale is popular everywhere due to its entertainment value. They are told mainly for amusement. "The characters in the Marchen are mainly anonymous. Secondly, there is no note of time and place and lastly, the story has a definite theme and a plot worked up to its natural conclusion"(Burne1914:262). All cultures in the world have their folktales. There is no known culture in the world where there is no folktale. Folktale is found everywhere (Thompson $1949: 408$ - 409).

Generally, the term 'folktale' refers to all kinds of traditional narrative. Till now, nobody has attempted to define the term exactly. "The characteristic feature of the folktale is the fact that it is traditional. It is handed down from one person to another, and there is no virtue in originality" (ibid : 408). Traditional stories can be divided into two classes-those told as true (myths and legends) and those told for amusement (folktales or marchen). Unlike the other narratives, folktales are very transmissible. "People who do not assimilate each other customs may assimilate each other tales" (Burne 1914:266). Similar tales may be found in two different countries which differ in their natural settings. In the tales of foreign origin, one finds various unfamiliar object and incident. On the other hand the tales found in a tradition include descriptions of familiar natural settings. Tales usually undergo a process of adaptation when they are borrowed. Such adaptation is called familiarization. Lauri Honko, one of the eminent folklorists of the world discussed about four forms of adaptation of tradition (1981:19-29).

It has been stated earlier that folktale is an important sub-division of folklore. With the publication of Grimm brothers "Kinder-und- Hausmarchen" in 1812, folktales became subject of serious study. It may be noted here that almost all folklore theories emerged as a result of studying the traditional tale. Various scholars developed many theories concerning origin, dissemination, variation, and meaning of the folktale. The current folktale study has been also greatly influenced by psychoanalytical theory propounded and developed by Sigmund Freud, Karl Abraham, Earnest Jones, C.G. Jung, Geza Roheim, Campbell, Dollard, Alan Dundes, A.K. Ramanujan and many more. Application of the psychoanalytic theory is useful to the extent that it helps us to interpret the symbolic elements which are found in the myths, legends and folktales. Folklore is artistic 
communication in a small group and some message underlying such communication can be known by the psychoanalytical interpretation of the various items of folklore (Islam $1985: 129$; Thompson $1951: 367$ ).

Psychoanalysis is a tool by which we can interpret the meaning of the different folklore items. Folklore - the knowledge and learning of people is incomplete without the aid of psychoanalysis. By analysing the lore in the light of psychoanalysis, we may understand the folk - the people. It is necessary to understand the folk their hopes, desires, needs and conflicts which is possible through psychoanalytical study and other methods.

It has been already stated that the study of folklore remains incomplete without interpreting the lore. Interpretation of folklore is necessary along with collection and classification of various folklore items. In order to understand the folk, we must collect products of their mind, classify them and interpret them with the help of some theories. So, mere collection of folklore item is not enough to understand the folk. Alan Dundes, a renowned folklorist opines, "There is nothing wrong with such collection. Quiet the contrary every discipline depends for its very existence on the continual gathering of raw material. Without such material, there would be nothing for analysts to analyse or interpreter to interpret" (1980: vii).

For many years, folklorists have been devoted themselves in collecting and classifying different folklore materials. There is relatively little interpretation of folklore. They give more importance on collection of the lore only. But the trend of modern research demands that the folklorists should be interested simultaneously in the study of 'folk' and 'lore' or in the study of the relationship between "folk" and "lore". Complete study of folklore is possible through collection, classification and interpretation of various folklore materials. When one turns to the question "Why" (rather than what) in the study of folklore, one enters into the area of interpretation. Every folklore item should be interpreted for clear understanding of the folk, how and why they create the lore (ibid: vii-ix ).

The area of interpretation in folklore is influenced by psychoanalytical theory. For interpretation of folklore items, folklorists leaned heavily on the theory of psychoanalysis. In myths, legends and folktales we find various symbolic elements which need to be interpreted ."Magic wands and dragons presumably don't exist in real life but they exist in folklore" and folklorists are more or less concerned with interpretation which is possible through psychoanalysis and other methods of analysis ( Dundes 1980 : viii ).

\subsection{Objectives}

1. To highlight the need and importance of folktale for maintaining wellbeing of society.

2. To understand the significance of psychoanalytical theory for folktale interpretation.

\subsection{Methodology} journals etc.

The present study is based on library work. Secondary data have been collected from various books,

\subsection{Meaning of Psychoanalysis}

\section{Theoratical Discussion}

The term 'psychoanalysis' has two accepted meanings. Firstly, it means a method of treating mentally disordered people. Secondly, it also goes to mean the theories on human mind and its various complexities. This psychoanalytical school is also known as depth psychology on the ground that it goes into the deep region of the unconscious mind (Chauhan $1978: 44)$.

Psychoanalytical theory was propounded by Sigmund Freud. Freud was originally a medical man who was engaged in the study and treatment of nervious patients in his own clinic. Out of his long devotion to medical practice he came to realise that many of the abnormal behaviour and mental disease of his patients were owing to the nervious abnormalities. Gradually he was more interested in the study of psychology and more particularly psychology of the unconscious mind (ibid : 45 ). In this regard main theoretical concepts of psychoanalysis may be discussed below.

\subsection{Three regions of mind}

According to Freud, our mind has three distinct regions. On the basis of his first discoveries concerning the psychology of psychoneurosis, dreams, jokes and of what he called the psychopathology of everyday life, such as slips of the tongue, of the pens, of memory he suggested a division of the mental activity into several parts that he called systems. One he called the system of unconscious, a second, a system of preconscious and a third a system of conscious. Since his ideas were first presented in "The interpretation of Dreams" (1900) it has often been assumed that the evidential basis for these theories came from his study of dreams.

The elements that are inaccessible to consciousness, or are accessible to it only with difficulty, and under special conditions, are grouped together as the unconscious (UCS). It is the mind in which all our pleasant and unpleasant experiences are accumulated, synthesized and organised. It is only by means of the techniques and the method of psychoanalysis that trace of this hidden chamber may be known. Elements that 
are readily accessible to consciousness when attention is directed to them make up the preconscious system (PCS). Elements in consciousness make up the conscious system (CS) (Brenner 1977 : 121).

\subsection{Importance of the unconscious}

So long psychology was devoted to the study and analysis of the conscious mind alone but psychoanalysis of Freud had attempted at the exploration of the unconscious mind and its various complexities. According to him conscious mind is a thin slight of the total mind like an iceberg. The larger portion of it exists below the surface of consciousness. The unconscious therefore comprises the larger part of the total mind which could not be ignored.

The term 'unconsciousness" cannot be said as devoid of consciousness, because it has its own mode and nature of functioning. Many of the behaviour action of man are prompted by this unconscious which remains unrecognised owing to our inexperience. Freud opined that in order to understand the causes of human behaviour our eyes should be directed towards this hidden chamber (ibid: 121 - 124)

\subsection{Evidence of the function of unconscious}

The unconscious mind and its contents all the time want to appear and come up to the level of consciousness. But the conscious region does not allow their indulgence and easy entrance to it. There is said to be "the censor" or "watch dog" - the gateway of consciousness against the intrusion of unpleasant elements. It is due to this reason that we cannot observe the function of unconscious mind in the state of consciousness. But Freud had evidently proved with the following points the presence of the unconscious mind and its function.

a) The post hypnotic condition suggests the function of unconscious mind.

b) Record of the dreams and their interpretation give evidence of the state of unconscious mind.

c) The muttering of the people in anaesthesia and bodily action in somnambulism indicate the activity of unconscious mind.

d) Solution of problem in dream indicates the unconscious mental function.

e) Various mistake committed in our daily life like slip of pen, slip of tongue, misreading, faulty action etc. are owing to the activity of the unconscious mind.

f) Moreover, psychoanalytic treatment and its remarkable success achieved in the field is the growing evidence of the unconscious mind (Chauhan $1978: 45$ ).

\subsection{Dream theory}

Dream occupies an important place in psychoanalytical research. Freud opined that dreams are psychical phenomena, they are not somatic or bodily action. For him, dream provided the royal road to the knowledge of the unconscious activities of the mind in the sense that it reflects the contents and processes of the unconscious mind. But the 'manifest content' of the dream is systematically disguised transformation of the 'latent content' which consists of the anxieties, impulses, wishes and ideas of unconscious mind.

The transformation of latent into manifest content is done by "dream work" (initiated by the dream censor). Its main function is to codify and disguise material which are subjected to repression. The latent material has been repressed because of its sexual, aggressive or frightening nature. In order to understand it, the course of the dream work has to be disentangled by "interpretation".

Freud's major publication "The Interpretation of Dreams" (1900) was an account of this process and the theory underlying it. The dream essentially expresses the fulfilment of a wish, which is painful or guilt laden to acknowledge consciously (Cheshire $1983: 161$ ).

\subsection{Infantile sexuality}

Freud believes in the early sexuality or sexual life of children. It had contradicted the general notion that sex instincts appear only at the onset of puberty. A child has his sexual instinct and activities from the very early stage and after an important course of development passing through many stages they lead to what is known as the normal sexuality of the adults. In this regard, the phases of psychosexual development may be mentioned below.

(a) Oral stage: From birth to one year of life of the child, the mouth is the principal region of the, dynamic activity. It is the first major area of excitation and energy. Early gratification of sex occurs through sucking of breast, thumb sucking, bitting etc.

(b) Anal stage: This stage generally ranges from two to three years. During this period, stimulation is focussed on eliminative functions through either holding back or letting go of the body's waste material. There is erogenous zone located in the anus.

(c) Phallic stage: This phase starts from the age of four years. At this stage the child is aware of his genitals and feels the pleasure out of it.

(d) The latency period: The latency period starts from five years of age. When the child enters into this stage, 
there is lessening of the sexual urge. Boys take interest in masculine things and ignore girls.

(e) Genital period: The beginning of this period is characterized by reawakening of sexual urges due to physiochemical changes associated with sexual maturity (Chauhan 1978: 47 - 48).

\subsection{Theory of repression}

Theory of repression is a very bold and convincing idea of Freud's psychoanalysis. Sex urges or libido which is the vital source of life cannot be realised in the reality owing to the prevailing social and cultural barriers. A person's illicit sex craving cannot be allowed to realise in its own way and he is rather ashamed of it in the society. He is therefore forced to repress or to remove the idea from his conscious mind.

But the problem does not end there. This struggle or striving continues to operate in our unconscious mind for whole life. The effort of our mind to remove unpleasant experiences from the conscious mind to the unconscious continues to operate in life. Repression is described as driving a desire deep into the region of unconscious mind. All the painful unpleasant and socially unacceptable tendencies are driven back to the unconscious by way of repression. It guards the conscious mind against inclusion of unpleasant experiences. So repression may be described as a defence mechanism of mind. According to Freud's theory, repression is the major pillar upon which rests the edifice of psychoanalysis. Most of the repressed elements and tendencies are derived out of sex instinct or libido (Freud $1971: 286$ - 302).

\subsection{Libido and various complexes}

According to psychoanalytical theory, sex urges or the libido is the vital force of life. "Libido" is a comprehensive term which includes all forms of love including love for the opposite sex. It concerns all race preserving the instincts of man. It is also known as "elan vital" or life force. Freud had maintained that libido forms various complexes in mind as an individual continues to grow and develop. Such complexes are the result of thwarting of the natural flow of the libido due to the cultural and social barrier. The father, mother, son, daughter relationships in the family life develop Oedipus complex and Electra complex in mind which are the manifestations of libido. Freud had described Narcissism or self love as the derivation of libido which is found to be active at the stage of infancy. Other two manifestation of libido are Masochism and Sadism. Masochism denotes "Sexual deviation in which an individual obtains sexual gratification from having pain inflicted upon him while in sadism sexual gratification is obtained by the infliction of pain upon others"(Coleman 1969: 665 670).

\subsection{The role of id, ego and super ego in formation of personality}

One of the valuable concepts of psychoanalysis is the threefold system in the organisation and building up of a man's personality. They are id, ego and super ego - constituting the psychic world of man. These may be known as the New Testament of Freudian scripture. The psycho- social build up of a man's personality is nothing but the result of these three systems.

In the year 1923, Freud proposed to divide the mental activity into id, ego and super ego instead of unconscious, preconscious and conscious. In the new theory, it is recognised that the three systems merge into one another and form a co-operative whole, except when there is conflict.

Freud conceived the id to be what he called the vital layer of the mind. He describes id as chaotic and a cauldron of seething excitement. It contains everything that is inherited, that is fixed in the constitution and is completely unconscious. Id is full of excitement and directly associated with somatic or bodily processes. Cut off from the external world, everything which goes on in the id is unconscious and remains so, having no correspondence to space or time. In the year 1933, Freud noted that the id contains sexual and aggressive energies, their discharge taking place with the help of the ego. The study of the id derivatives indicates that there are many contradictory impulses present in the id and the ego is required to put them in order.

This "kingdom of the illogical" as Freud (1940) called it, is completely unconscious containing various instinctual impulses. The id is only interested in the discharge of instinctual tension and is always guided by 'hedonism' or the pleasure principle. The activity of the id is governed by the so called primary process, in which there is no recognition of good and bad, or yes or no. The principal feature of the primary process is a tendency to the complete discharge of mental energies - without delay. The id has no connection with the external world, but opens towards the ego. It is separated from the ego by its censor, which controls the flow of id derivatives. In addition to communicating with the ego, the id also communicates with the super ego. The id supplies both ego and super ego with the energies with which they operate.

Id is inherited and fixed part of the personality which contains the instinctual, elemental or emotional drives that provide the psychic energy for human behaviour. These forces are modified and transformed by other parts of the personality which develop out of the id, notably the ego and super ego.

The ego represents the self and is concerned with external reality and decision making. The ego is in constant contact with time, space and with physical reality. It has organizational and critical capacity. Its 
function is to establish relationship between the individual organism and the outer world. The contact with reality compels the ego to adopt the reality principle and to abandon the pleasure principle which dominates the id. The ego is an adjuster between the wishes of the id on the one hand and the demands of external reality on the other. At the same time, it has to obey the demands of the super ego. So the ego has to serve three harsh masters at a time.

Due to this reason, there is always conflict among these three systems. It the ego cannot fulfil the demands of the id, it takes help of some indirect method called defence mechanism. Defence mechanisms are the mode of behaviour to relief the ego from tension.

The third system, the super ego may be defined "as the group of mental functions having to do with ideal aspirations and with moral commands and prohibitions" (Brenner 1977: 124). The super ego provides moral conscience and ideal model which the person may seek to emulate. It is primarily sociologically and culturally conditioned and strives for perfection rather than pleasure (Brenner 1977 : 120 - 124 ; Eidelberg 1968 : 183).

\section{Folktale and Psychoanalysis}

It has been stated earlier that in the study of folktale and other items of folklore, psychoanalytical theory can play a major role. Folktale is an important genre of folklore. Tales are told for amusement which reflects the fantasies of a people metaphorically. The analysis and interpretation of metaphors provide unrivalled insights into the social problems and behaviour of people everywhere. It is not enough to say that folklore is a mirror of a culture. We must try to see what it is that folklore reflects. For that we have to depend on psychoanalytical theory which helps in interpretation of any folklore item. Interpreting means here finding a hidden sense in something.

From Freud's study of dreams, psychological theories relating to the folktale have received new incentive. Dreams can reflect the personal mental life and especially the anxieties of an individual. During sleep the defences of the ego are lowered allowing repressed materials to reach the conscious. For this reason dreams to some extent, may taken as royal road to the unconscious. The contents of the dream are usually symbolic and a proper interpretation of the symbols by an expert psychoanalyst may provide valuable clues to repressed desires and conflicts of the people. The people obtain fulfilment in imagination of those unconscious wishes which it cannot obtain in reality. Like dreams, myths and other folklore items also reveal psychic repressions of the community. Due to this reason, psychoanalysts consider folklore as the projection of human mind. Karl Abraham, a renowned member of Freudian school opined that the dream is the myth of the individual (Dorson $1972: 26)$.

Projection is an act of externalizing the conflicts and other internal conditions that give rise to pain and anxiety in person. It provides an opportunity to evoke responses from the unconscious mind which reveal the person's wishes. The repressed hopes and desires of a society are expressed in various folklore items. Folklore is a medium through which a folk community reveal their repressed feelings. From that point we can define folklore as a defence mechanism of the society, through which a society maintain its well being by releasing pent up tensions. Because we know that repressed desires and hopes are the root of all evils.

From the above discussion it is evident that there is a close relationship between folklore and psychoanalysis. Earnest Jones (1879 _ 1959) the close friend and biographer of Freud, delivered a lecture on "psychoanalysis and folklore" addressing the English Folklore Society at their fiftieth anniversary congress in 1928. (Dorson $1972: 26$ - 27).

Folktale is very popular among the various items of folklore. Like any other items of folklore, folktale also reflects the unconscious needs and demands of the members of a society. Folktales are the products of human mind. What instigates a tale is a wish and the fulfilment of that wish is the content of the tale. Due to this reason, folktale is the most popular amongst all the narratives. People find pleasure in it since it satisfies a wish. Generally all tales have a happy ending and the child identifies itself to a varying extent with the young hero of the story. The child obtains a fulfilment of those unconscious wishes which it cannot yet obtain in reality. Folktale is a medium through which people project their emotional life into a safe, externalized, socially sanctioned form (Islam $1985: 130$ ).

All folktales reflect the need and hopes of a society symbolically. In folktales we find many symbolic figures and "properly understood and logically arranged symbol figures told a story of sexual hunger, guilt and shame. Beneath the manifest content lurks a latent fantasy of masturbation, castration, body destruction, penisenvy, incest" (Dorson 1972 : 26). In order to decipher latent meanings of folktale folklorists learned heavily on the theory of psychoanalysis. Various types of folktales have been interpreted by many scholars following Freudian line. In this regard, two renowned folklorist of India, J. Handoo and A. K. Ramanujan's name may be mentioned here who have done analytical works in terms of psychoanalytical interpretation. 


\section{Conclusion}

For proper understanding of a society, psychoanalytical study of folktale may be considered essential. Through various characters of the folktale a society reduces its anxiety and tension resulting from unrealised needs and hopes. Each and every society has their own norms and values which are necessary for its members to follow. Because of social control the people cannot fulfil their hopes and desires. The repressed materials find place in the dreams, myths and other folklore materials. Folktale is a medium through which a folk community reveal their repressed feelings. From that point of view we can define folktale as a defence mechanism of the society, through which a society maintain its well being by releasing pent up tensions. Because we know that repressed desires and hopes are the root of all evils. Folktale reflects the unconscious needs and demands of the members of a society metaphorically. These are the products of human mind. What instigates a tale is a wish and fulfilment of that wish is the content of the tale. And people find pleasure in it since it satisfies a wish. Study of folktale in the light of psychoanalytical theory proves to be useful in understanding human behaviour and social problem. At the same time some other psychological or sociological approaches may also be used in the analysis of folktale.

\section{References}

[1]. Alan Dundes, 1975. Analytical essays in Folklore (Mouton Publishers: The Hague, 1975)

[2]. Alan Dundes, Interpreting Folklore (Indiana University Press Bloomington, 1980)

[3]. Alan Dundes, The study of Folklore ( Englewood Cliffs: Prentice Hall, 1965)

[4]. Alan Dundes, Fire in the dragon and other psychoanalytic essays on folklore( Princeton University Press: New Jersey, 1912 )

[5]. Sand Aarne Thompson, (ed.) The Types of the Folktale (Indiana University: Helsinki, 1961)

[6]. Metraux, "Trickster", In Standard Dictionary of Folklore, Mythology and Legend ed. by Maria Leach Vol.2 ( Funk and Wagnalls Company: New York, 1949)

[7]. Datta, A Handbook of Folklore material of North-East India ( ABILAC, Assam: Guwahati, 1984)

[8]. Datta, Focus on Folklore of North-East India. Special volume numbers One and Two (1983-84 and 1984-85) of The Assam Academy Review.

[9]. Brenner, Freud's structural model, The superego, In Benjamin B. Wolman (ed.) International encyclopaedia of psychiatry, psychology, psychoanalysis and neurology, Vol. 5. (Von Nostrand Reinhold Company, 1977).

[10]. C.S. Burne, The Handbook of Folklore (Sidgwick and Jackson Limited: London, 1914)

[11]. J.C. Coleman, Abnormal psychology and modern life ( D. B. Taraporevala Sons \& Co. Private Ltd. by arrangement with Scott, Foresman and Company: Bombay, 1969)

[12]. J. Handoo, Folklore - An Introduction( Central Institute of Indian Languages, Mysore, 1989)

[13]. J. Sand Balys Thompson, The oral tales of India (Indiana University Press: Bloomington, 1958)

[14]. L. Eidelberg, "Id", "Autoerotism", "Castration anxiety", In Encyclopedia of psychoanalysis( The Free Press: London, 1968)

[15]. Land Voigt Honko, Adaptation, change and decline on Oral literature( Helsinki, 1981)

[16]. M. Islam, Folklore: The pulse of the people ( Concept Publishing Company, New Delhi, 1985)

[17]. N. N. Cheshire, "Dream theories","Defence mechanism". In Rome Harre and Roger Lamb (ed.) Encyclopaedic Dictionary of Psychology (Basil Blackwell Publisher Limited: Oxford, 1983)

[18]. P. Goswami, Ballads and Tales of Assam (Department of Publication. University of Gauhati, 1960)

[19]. P. Goswami, Tales of Assam ( Publication Board, Assam, Gauhati, 1980)

[20]. P. Goswami, Essay on the Folklore and Culture of N. E. India ( Spectrum Publications, Guwahati, 1982)

[21]. R.M. Dorson, Folklore and Folklife (The University of Chicago Press: Chicago and London,1972).

[22]. S. S. Chauhan, Advanced Educational Psychology (Vikas Publishing House Pvt. Ltd. New Delhi, 1978).

[23]. S. Freud, The Complete Introductory Lectures on Psychoanalysis (ed. by James Strachey Alden Press: Oxford, 1971)

[24]. S. K. Mangal, Abnormal Psychology ( Sterling Publishing Private Limited: New Delhi, 1984)

[25]. S. Thompson, The Folktale (The Dryden Press: New York, 1952)

[26]. S. Thompson, "Folktale", In Standard Dictionary of Folklore, Mythology and Legend. ed. by Maria Leach Vol. 1 ( Funk and Wagnalls Company: New York, 1949)

[27]. T. Coffin, American Folklore( Washington D.C. 1968) 